\title{
Política y rebelión en el siglo xv andaluz: la situación cordobesa ante la expedición del infante Enrique (1443-1445) ${ }^{1}$
}

\author{
Politics and Rebellion in Fifteenth-Century Andalusia: \\ The Situation in Cordoba during the Infante Henry's Expedition (1443-1445)
}

\author{
Óscar Villarroel GonZÁLEZ ${ }^{2}$ \\ Universidad Complutense. Madrid \\ ovillarroel@ghis.ucm.es
}

\begin{abstract}
RESUMEN
Durante los años 1443 y 1445 se produjo una expedición militar del infante Enrique de Aragón en Andalucía, mientras el rey Juan II de Castilla estaba en manos del infante Juan de Aragón, que buscó poner bajo su control todo el sur del reino castellano. En Córdoba, el infante se encontró con diversos apoyos y resistencias, que fueron consecuencia y causa de los cambios en la posición política de algunos importantes personajes del reino.
\end{abstract}

Palabras clave: Castilla. Siglo xv. Córdoba. Enrique de Aragón. "Infantes de Aragón”. Sancho de Cordoba. Rebelión

\begin{abstract}
The Infante Henry of Aragon's military expedition in Andalusia, which sought to control the whole south of the kingdom of Castile. In Cordoba, took place during the years 1443 and 1445, while the king, John II of Castile, was in the hands of the Infante John of Aragon. The infante Henry met diverse allies and opponents, who were a consequence and cause of the changes in the political positions of certain important personages of the kingdom.
\end{abstract}

Keywords: Castile. 15th century. Cordoba. Henry of Aragon. "Infantes of Aragon". Sancho of Cordoba. Rebellion

Sumario: 1. El golpe de Rámaga y el inicio de la campaña andaluza. 2. El infante en Córdoba: acordes y desacuerdos. 3. Los orígenes familiares del enfrentamiento. 4. La resistencia al bando del infante. 5. Las consecuencias de la rebeldía. 6. A modo de conclusión

\footnotetext{
${ }^{1}$ El presente trabajo se enmarca dentro del Proyecto de Investigación del Ministerio de Ciencia e Innovación n. ${ }^{\circ}$ HUM 2006-05233, con el título Las relaciones de conf icto en sus prácticas representativas (La Corona de Castilla en su contexto europeo, siglos XII -XV), y fue presentado en el VII Coloquio de Historia de Andalucía (Granada, 2007).

${ }^{2}$ A lo largo del presente trabajo se utilizarán las siguientes siglas: ASV (Archivio Segreto Vaticano), Reg. Vat.. (Registra Vaticana), ACC (Archivo Capitular de Córdoba), AHNN (Sección Nobleza del Archivo Histórico Nacional, Toledo), AMCO (Archivo Municipal de Córdoba), y AM (Archivo Municipal). 
El 9 de julio de 1443 se producía el Golpe de Estado de Rámaga, mediante el cual los infantes de Aragón (Enrique y Juan, rey de Navarra) asumieron el control de la persona de Juan II y del poder regio castellano. El monarca quedaba incomunicado y sometido a los infantes, no pudiendo llevar a cabo ninguna actividad, ni de gobierno ni de cualquier otro tipo, sin la autorización de sus primos. El rey era su prisionero y el reino estaba en sus manos.

En este contexto se desarrolló la expedición andaluza del infante Enrique, cuyos objetivos no están muy claros y son debatidos por la historiografía. Hace años Eloy Benito Ruano indicó, siguiendo lo que las crónicas nos transmiten, que la actuación parecía deberse a la propia iniciativa regia, debido a los problemas que en Andalucía, y en Sevilla y Niebla específicamente, estaba causando el enfrentamiento entre los bandos nobiliarios, aprovechando posteriormente el infante el Golpe de Rámaga para ocupar el sur de la península (pero sin indicar una clara motivación para ello) ${ }^{3}$. Emilio Cabrera propuso recientemente que todo se incardinaba dentro de un plan de los infantes para otorgar Andalucía al infante Enrique con un amplio grado de soberanía, con intenciones, incluso, de independencia ${ }^{4}$.

Sea como fuere, y tuviese las intenciones que tuviese el infante, lo cierto es que se produjo un amplio enfrentamiento entre aquellos que eran defensores de la autoridad regia y los que apoyaban a los infantes, puestos bajo el mando del infante Enrique que acudió a Andalucía en una auténtica campaña de conquista. El caso más conocido es el de Sevilla, que hubo de resistir un largo asedio y recibir ayuda exterior, pero tales enfrentamientos no fueron únicos. En el caso de Córdoba, la historiografía ha tratado estos conflictos de forma tangencial. Tangencial en el sentido de que se ha dado un acercamiento al tema, bien en el momento de tratar el conflicto en su contexto andaluz o sevillano ${ }^{5}$, al estudiar una casa nobiliaria que tuvo actuación o participación en el caso cordobés y/o andaluz ${ }^{6}$, cuando se analiza la personalidad de los prelados cordobeses ${ }^{7}$, o incluso en el momento de estudiar la conflictividad urbana $^{8}$. Sin embargo, aún se puede conocer, siquiera un poco más, cómo sucedieron los hechos en Córdoba, gracias a la documentación conservada tanto en el Archivo Capitular, como en el Archivo Histórico Municipal, junto a diversos testimonios

${ }^{3}$ E. Bentto Ruano, «La expedición portuguesa de 1444 en socorro de Sevilla», Actas das II Jornadas Luso-Espanholas de Historia Medieval, Oporto, 1987, I, pp. 333-355.

${ }^{4}$ Véase al respecto: E. CABRERA, «Andalucía y los Infantes de Aragón», Acta historica et archaeologica mediaevalia, 22 (2001), ejemplar dedicado a homenaje al doctor Riu Riu, II, pp. 699-720.

${ }^{5}$ Véase el mencionado trabajo del profesor Eloy Benito Ruano.

${ }^{6}$ Véanse al respecto los trabajos de Quintanilla Raso y Cabrera: M.C. Quintanilla Raso, Nobleza y señoríos en el Reino de Córdoba. La casa de Aguilar (siglos XIV y XV), Córdoba, 1979. en concreto las páginas 90-91, 94-95, y 174-175; E. CABRERA, El condado de Belalcázar (1444-1518). Aportación al estudio del régimen señorial en la Edad Media, Córdoba, 1977, pp. 114-120.

${ }^{7}$ I. SAnZ SANCho, «Los obispos del siglo xv», Hispania Sacra, 54 (2002), pp. 605-678; también, aunque de forma más superficial y tangencial, al tratar otros temas, en su más reciente: La Iglesia de Córdoba (1236-1454). Una diócesis de la pr ovincia eclesiástica de Toledo en la Baja Edad Media , Madrid, 2006, p. 188.

${ }^{8}$ F. Mazo Romero, «Problemas internos y tensiones sociales en el municipio cordobés durante la primera mitad del siglo xv», Actas del I Congreso de Historia de Andalucía. II. Andalucía medieval, Córdoba, 1978, pp. 85-115. 
de origen nobiliario tanto inéditos como publicados o ya utilizados anteriormente por algunos historiadores. Como veremos a continuación, gracias a ellos podemos apreciar la evolución de los hechos, el surgimiento de la resistencia al dominio de la ciudad por los partidarios de los infantes, así como las consecuencias de los diferentes participantes en los movimientos políticos, tanto los favorables al rey como los opuestos. Pese a que el conocimiento exacto de algunas fechas es algo que se nos escapa, la evolución cronológica parece la forma más acertada de acercamiento a los sucesos ocurridos en Córdoba.

\section{EL GOLPE DE RÁMAGA Y EL INICIO DE LA CAMPAÑA ANDALUZA}

Así pues, el 9 de julio de 1443 se producía el Golpe de Rámaga, por medio del cual los infantes se hacían con el poder en Castilla. Desde ese momento el rey no podía hablar en secreto con nadie sin consentimiento del infante Juan y del príncipe, pasando el monarca a estar en una situación cercana a la prisión (al menos tal y como se consideraba en la época la prisión de altos personajes) ${ }^{9}$. El golpe fue convenientemente matizado y mostrado a las ciudades del reino como una liberación del rey de aquellos que le oprimían (refiriéndose sobre todo a Pérez de Vivero) por parte de sus fieles servidores (el infante y el príncipe ${ }^{10}$. No obstante, el príncipe pronto se desvincularía de tal actuación, gracias a la labor de Lope de Barrientos, quien sería el principal valedor de la libertad del monarca" ${ }^{11}$. Desde ese momento los infantes pasarían a dominar Castilla, el infante Juan la corte y el norte del reino, el infante Enrique el sur del mismo.

El dominio del infante Enrique del sur de la Corona podemos considerarlo un hecho desde el Sistema Central. Por un lado tenía bajo su autoridad los extensos territorios de la Orden de Santiago, de la que había recuperado el control tras su entrada en Castilla, y por otro lado se hizo con el control de la Orden de Calatrava, en principio para que fuese entregada a uno de los candidatos al maestrazgo: su sobrino Alfonso de Aragón. Para ello no dudó en poner sitio y ocupar el convento de Calatrava' ${ }^{2}$. El control de la zona meridional del reino, y en concreto de La Mancha y Toledo, fue algo apreciado incluso en aquellos momentos. Así, Pedro de Escavias,

${ }^{9}$ L. Galíndez de Carvajal, Crónica del serenísimo príncipe don Juan II de Castilla, ed. Cayetano Rosell, en el tomo II de las Crónicas de los Reyes de Castilla , Biblioteca de Autores Españoles, 68, Madrid, 1953, p. 613.

${ }^{10}$ Véase al respecto la que se envió al concejo de Murcia: AM Murcia, Cartas antiguas y modernas, VIII, 55; documento publicado por J. Abellán Pérez, Colección de documentos para la historia del Reino de Mur cia. Documentos de Juan II, (volumen $15^{\circ}$ de la colección), Murcia-Cádiz, 1984, pp. 570-571. Con ello se repetían los pasos que el infante Enrique dio tras el Golpe de Tordesillas, quien también escribió a los concejos.

${ }^{11}$ P. Carrillo de Huete, Crónica del halconero de Juan II de Castilla, ed. Juan de Mata Carriazo y Arroquia, Madrid, 1946, pp. 435 y ss. La autoría de la crónica en este periodo, empero y desde mi punto de vista, deberíamos asignársela a Lope de Barrientos, según indica F. Gómez Redondo, Historia de la prosa medieval castellana. III. Los orígenes del humanismo. El mar co cultural de Enrique III y Juan II, Madrid, 2002, p. 2273.

${ }^{12}$ L. Galíndez de Carvajal, Crónica del serenísimo ..., pp. 612-613. 
poniendo las palabras en boca del infante Enrique, decía años después: "vime señor de Toledo" ${ }^{13}$. Alonso de Palencia también nos transmite cómo el infante dominaba en ese momento el reino toledano: "emprendió don Enrique, dueño también de Toledo, la marcha a Andalucía" ${ }^{14}$. Con el rey prisionero, además, había sido fácil conseguir del papa el nombramiento de maestre para el candidato de los infantes, al presentarse como una petición del propio rey ${ }^{15}$.

Desde ese momento, y so pretexto de las querellas por el título de conde de Niebla, realizaría una expedición a Andalucía que, más que una pacificación, supuso una auténtica conquista. Esta expedición habría sido ordenada por el propio monarca, concediendo a su primo poderes suficientes ${ }^{16}$. Sin duda, el dominio de los infantes sobre el rey se pone de este modo de manifiesto, así como el intento de éstos de legitimar la posterior acción del infante.

\section{EL INFANTE EN CÓRDOBA: ACUERDOS Y DESACUERDOS}

No sabemos la fecha exacta en la que el infante consiguió entrar en Córdoba. Podemos, sin embargo, deducirla o, al menos, sospecharla. Sabemos que a mediados de noviembre comenzaban a darse movimientos políticos en Sevilla, con vistas a la oposición a la posible llegada de rivales regios. Así, el día 15 Juan de Guzmán, el adelantado Per Afán de Ribera, Pedro de Guzmán y el prior cartujo Fernando de Torres, junto al alcalde Rodrigo Rodríguez, se comprometían a defenderse mutuamente y al poder regio ${ }^{17}$. Para entonces ya había abandonado el bando regio Pedro Ponce de León, quien en un principio se había confederado con los defensores ${ }^{18}$. Además, desde principios de diciembre ya tenemos constancia de que el concejo de Sevilla estaba en comunicación con el regente portugués para conseguir auxilio militar ${ }^{19}$. Es decir, para entonces ya temían o sabían que el infante iba a acudir a Sevilla y tenían intención de resistirle.

Desde principios del año siguiente comenzamos a tener noticias fidedignas de que la ciudad de Córdoba se encontraba ya en manos del infante Enrique. Para empezar, el día 20 de enero el concejo de Córdoba ordenó a los jurados de Santa Marina colaborar con el infante Enrique y que se le diesen gentes de caballo y de a pie para tomar la villa de la Puebla ${ }^{20}$. Ya desde estos momentos, además, podemos ver en la documentación el reflejo de la división que se había producido en la nobleza cordobesa por la llegada del infante Enrique. En primer lugar, el cabeza de la familia de

${ }^{13}$ Sobre este autor y obra, véase: E. Benito Ruano, «Fortuna literaria del infante don Enrique de Aragón», Archivum, 14 (1964), pp. 161-201.

${ }^{14}$ A. De Palencia, Crónica de Enrique IV de Castilla, edición e introducción de A. de Paz y Meliá, Biblioteca de Autores Españoles, Madrid, 1973, p. 16a.

${ }^{15}$ ASV, Reg. Vat., 362, ff. 66v-68r. Documento emitido el 4 de septiembre de ese mismo año, se encargó de su ejecución a los obispos de Osma, Palencia y Córdoba.

${ }^{16}$ L. Galíndez de Carvajal, Crónica del serenísimo príncipe..., p. 612.

${ }^{17}$ AM Sevilla, Actas capitulares, 1443, nov-dic, f. $28 \mathrm{r}$.

${ }^{18}$ E. Benito Ruano, «La expedición portuguesa...», p. 336.

${ }^{19}$ Ibídem, p. 337.

${ }^{20}$ M.C. Quintanilla Raso, Nobleza y señoríos..., p. 90. 
los señores de Aguilar, Pedro Fernández de Córdoba, junto a sus familiares, tenían que abandonar la ciudad (para lo que el infante le concedió un seguro) sin tropas que les acompañasen ${ }^{21}$.

Los beneficiarios de esta ausencia serían, sin duda, los linajes de Baena y Montemayor (ramas de la misma familia Fernández de Córdoba) y que estaban enfrentados a los Aguilar ${ }^{22}$. Esta rivalidad, en el caso de los linajes de Aguilar y Baena, tenía su origen, sin duda en la lucha por la preeminencia entre la nobleza cordobesa ${ }^{23}$, en lo que suponía un eco de los conflictos del conjunto general del reino.

Y todo esto tuvo también su reflejo eclesiástico, pues en el cabildo cordobés se repetía la división de la nobleza comarcal. Si ya detectamos enfrentamientos previos con los Fernández de Córdoba en 1442, durante 1443 la situación de división se hizo más patente ${ }^{24}$. A principios de diciembre ya debía estar próxima la entrada de las tropas del infante en Córdoba, lo que habría supuesto la huida de algunos miembros de la familia Fernández de Córdoba. Esto podemos sospecharlo por el hecho de que se aprobase el día 3 de diciembre un estatuto capitular por el cual los miembros del cabildo que estuviesen ausentes podrían cobrar sus rentas como si estuviesen en Córdoba, a lo que, infructuosamente, se opuso el obispo ${ }^{25}$. El hecho de que el origen de los capitulares fuese el punto fundamental en tal negativa lo encontramos en el hecho de que el prelado no se opuso el 23 de diciembre de ese mismo año a que Diego Fernández de Montemayor y Pedro Fernández, ambos canónigos, cobrasen sus rentas pese a estar fuera ${ }^{26}$. Como vemos gracias al apellido del primer capitular, la pertenencia a un linaje aliado del propio fue sin duda la razón para que el obispo se contradijese a sí mismo. Esta contradicción es palmaria cuando vemos que el prelado consiguió paralizar la ordenanza capitular en mayo de $1444^{27}$. Sin duda en esos momentos, con todos sus rivales fuera de la ciudad, se trataba de un claro ataque económico contra ellos.

\section{LOS ORÍGENES FAMILIARES DEL ENFRENTAMIENTO}

Pero ¿de dónde venía la alineación de los señores de Baena con los rivales regios? Ya en 1442 vemos cómo se producía tal alianza, que amenazaba con la ocupación de

${ }^{21}$ J.M. Nieto Cumplido, Corpus medievale Cordubense, 1444 (I), 1444, 01, 20. Trabajo inédito en lo referente a esta época y conservado en el ACC. Hago constar aquí mi agradecimiento al doctor NIETO Cumplido por permitirme la consulta de su obra.

${ }^{22}$ Ibídem, p. 162. Un ejemplo de la unión de los Baena y los Montemayor lo encontramos en el matrimonio de Pedro Fernández de Córdoba, II señor de Baena, con Juana Fernández de Córdoba Montemayor (AHNN, Baena, c. 8, doc. 4). Ambos serían los progenitores del cabeza de la familia Baena en estos momentos: Diego Fernández de Córdoba II. Sobre el matrimonio entre la nobleza cordobesa, véase: M.C. Quintanilla Raso, «Estructuras sociales y familiares y papel político de la nobleza cordobesa (siglos XIV y Xv)», En la España Medieval, 3 (1982), pp. 331-352, p. 343 y ss.

${ }^{23}$ Ibídem, p. 340.

${ }^{24}$ I. SANZ SANCHO, «Los obispos del siglo xv», p. 617 y ss.

${ }^{25}$ Ibídem, p. 617, cita las Actas Capitulares cordobesas, pero sin indicar localización, que podemos sospechar gracias a la fecha.

${ }^{26}$ Ídem.

27 Ídem. 
la ciudad de Córdoba por los rebeldes al rey, lo que supuso que Juan II acudiese a los señores de Aguilar para defenderla ${ }^{28}$. No obstante, el posible enfrentamiento venía de antes. Si nos retrotraemos más en el tiempo, ya en 1439 el obispo Sancho de Rojas se había unido a la nobleza rebelde en Valladolid ${ }^{29}$, en el que fue el primer síntoma de esa adhesión a los rivales regios.

La actuación del por entonces obispo astoricense tiene claras raíces familiares. Sancho de Rojas era el tercer hijo de Diego Fernández de Córdoba, mariscal de Castilla y primer señor de Baena, y su primera esposa Sancha de Rojas ${ }^{30}$. Éste Diego Fernández había fundado dos mayorazgos para sus hijos: el mayor, Juan Rodríguez, heredó el mayorazgo de Poza (fundado sobre los bienes aportados por su mujer en el reino de Toledo), y el segundo, Pedro Fernández, el de Baena (fundado sobre los bienes heredados de su padre Fernán Alfonso de Córdoba, señor de la casa de Aguilar) ${ }^{31}$.

$\mathrm{Y}$ el origen del motivo para esa actuación familiar tal vez lo debamos buscar unos años atrás. El 9 de septiembre de 1435, al morir Pedro Fernández de Córdoba, guarda hasta ese momento del príncipe Enrique, el monarca entregó ese cargo al condestable Álvaro de Luna ${ }^{32}$. ¿Acaso la familia se sintió desplazada por el condestable, pues esperaba que el hijo del difunto (y sobrino del obispo Rojas) recibiese la guarda que ostentaba su padre? Es posible; el rey, sin embargo, debía ser consciente del menosprecio, pues poco después, el 15 de octubre de ese mismo año entregaba a Diego Fernández de Córdoba, III señor de Baena e hijo del difunto, los oficios de alguacil y alcalde mayor de la villa de Iznájar ${ }^{33}$. Incluso en 1439 , una vez que ya habían abandonado su bando al apoyar a los sublevados, el rey intentaría atraérselos por medio de la donación de Cabra ${ }^{34}$

Como hemos visto, sin embargo, no serviría de nada, puesto que tendría que recurrir a los señores de Aguilar para retener a la nobleza. Así, en Córdoba, los linajes menores de la rama Fernández de Córdoba (Baena y Montemayor) quedaban

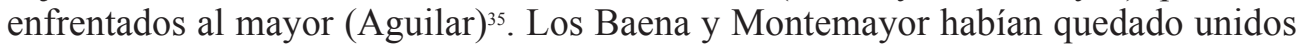
por el matrimonio de Pedro Fernández de Córdoba con Juana Fernández de Montemayor ${ }^{36}$, con lo que Diego Fernández, hijo de ambos, mantenía fuertes lazos con ambos linajes.

${ }^{28}$ M.C. Quintanilla Raso, «El dominio de las ciudades por la nobleza. El caso de Córdoba en la segunda mitad del siglo xv», En la España Medieval, 6 (1987), pp. 109-123, especialmente p. 112.

29 L. Galíndez de Carvajal, Crónica del ser enísimo príncipe..., p. 552; P. Carrillo de Huete, Crónica del Halconero..., p. 282.

${ }^{30}$ Esta filiación, transmitida por la genealogía, puede comprobarse en el testamento de Diego Fernández de Córdoba, AHNN, Baena, C. 24, doc. 6.

${ }^{31}$ Ibídem, Carp. 8, doc. 24.

${ }^{32}$ L. Barrientos, Refundición de la crónica del halconer o, ed. J. de M. Carriazo y Arroquia, Madrid, 1947, p. 197. Pese a la atribución de Arroquia, esta obra cronística debería asignarse a Pérez de Guzmán, F. Gómez Redondo, Historia de la prosa medieval castellana, vol. III Los orígenes del humanismo. Los reinados de Enrique III y Juan II, Madrid, 2002, p. 2322.

${ }^{33}$ AHNN, Baena, c. 128, doc. 2-3.

${ }^{34}$ Ibídem, doc. 30-33.

${ }^{35}$ Sobre la nobleza cordobesa véase: M.C Quintanilla Raso, Nobleza y señoríos... En cuanto a la unión de estos dos linajes, véase especialmente pp. 163, y sobre la época también p. 175.

${ }^{36}$ AHNN, Baena, carp. 8, doc. 4. 


\section{LA RESISTENCIA AL BANDO DEL INFANTE}

Así pues, desde principios del año 1444 sabemos que Córdoba estaba dominada por los partidarios del infante Enrique, encabezados por los señores de Baena, que controlaban la ciudad gracias a la salida de la misma de los señores de Aguilar. Sin duda, Diego Fernández de Córdoba se apoyaba para ello en su puesto de veinticuatro ${ }^{37}$.

Ese control se mostraría pronto por medio de diversas iniciativas. El concejo, sin duda encabezado por Diego Fernández, ordenó a los jurados de Santa Marina colaborar con el-infante Enrique con tropas de a pie y a caballo, para que pudiese ocupar la villa de La Puebla ${ }^{38}$. Tropas que posiblemente acudiesen junto al infante para tomar Sevilla ${ }^{39}$, junto a otras de Jaén ${ }^{40}$.

La situación, sin embargo, empezaría a empeorar rápidamente, puesto que el infante se encontró con fuerte resistencia en Sevilla. La reacción, incluida la inminente ayuda portuguesa ${ }^{41}$, le haría incurrir en mayores gastos, lo que tendría como reflejo un intento de atracción por su parte de las rentas regias de las zonas que controlaba.

Esta tentativa del infante de conseguir recaudar las rentas regias en Andalucía llegaría a oídos del príncipe Enrique quien, preparando ya la liberación de su padre junto al obispo Barrientos, no dudaría en escribir a todos los concejos para que resistiesen y no entregasen rentas sino a sus propios enviados, de forma que sirviesen para liberar al rey ${ }^{42}$. El príncipe informó de que tales intentos de recaudación se estaban llevando a cabo por parte de infantes, duques, marqueses, prelados y grandes del reino. La cronística del reino llegó a hacerse eco de esta situación, al ser la liberación de las rentas regias una de las condiciones que el príncipe ponía al infante Juan para derramar sus tropas ${ }^{43}$. Esta situación se dio de forma efectiva en Córdoba ${ }^{44}$.

La situación empeoraría rápidamente para el infante en Andalucía, pese a que aún podía contar con que su hermano tenía al rey cautivo. En abril de ese año entraban en Sevilla los refuerzos de los maestres de Alcántara y Calatrava, lo que, unido a la amenaza portuguesa, hacía muy difícil ya que lograse entrar en la capital hispalense ${ }^{45}$. Esto haría, sin duda, que buscase convencer a los concejos de que escribiesen

${ }^{37}$ Ya ostentaba este cargo al menos en enero de 1442, AMCO, Archivo Histórico, C-0262-001.

${ }^{38}$ J. M. Nieto Cumplido, Corpus medievale, 1444 (I).

${ }^{39}$ E. Benito Ruano, «La expedición portuguesa de $1444 \ldots$... p. 335.

${ }^{40}$ Ibídem, efectivamente el obispo giennense también colaboró con los infantes, encontrándose ejemplos de su oposición a las órdenes regias: por ejemplo, en 1444 se resistió a la orden regia que le obligaba a levantar el entredicho que había impuesto sobre Baeza, sin duda por la actuación del concejo favorable al rey: A. DE LA Fuente GonzÁlez, Don Gonzalo de Stúñiga, obispo de Jaén (1423-1456), Córdoba, 1978, p. 95.

${ }^{41}$ Véase al respecto el trabajo citado de E. Benito RuAno.

${ }^{42}$ Archivo General de Simancas, Cámara de Castilla, Diversos de Castilla, leg. 4, nº 59.

${ }^{43}$ L. Galíndez de Carvajal, Crónica del serenísimo príncipe..., p. 621.

${ }^{44}$ Noticia de ello en: ACC, Caj. JHS, n. ${ }^{\circ} 399$.

${ }^{45}$ E: Benito RuANo, «La expedición portuguesa de $1444 \ldots »$, p. 347. 
al rey instando a la expulsión de los portugueses ${ }^{46}$. Empero, a principios de mayo ya había perdido la villa de Carmona ${ }^{47}$.

Tal vez por ello, desde Córdoba, se intentó evitar que los que colaboraban con el rey recibiesen rentas desde territorio cordobés. Así, Sancho de Rojas ordenó al cabildo el 4 de mayo que se suspendiese la ordenanza capitular que permitía a los ausentes cobrar sus rentas ${ }^{48}$. Su poder sobre el cabildo, entonces, debía ser importante, pues accedieron. Pero duraría poco. Es posible que, ante la perspectiva de un cambio en la situación, los capitulares decidiesen comenzar a presentar resistencia al obispo, pues el día 24 de julio volvieron a establecer en su totalidad la ordenanza que permitía cobrar las rentas pese a la ausencia. Esto beneficiaba, sin duda, a los miembros del cabildo que desde fuera de Córdoba colaboraban con el rey, como podría ser el caso de Fernando Ruiz de Aguayo.

Para entonces la situación en la ciudad era ya muy inestable, con alborotos y desórdenes callejeros. Tales serían las circunstancias que ese mismo mes los jurados de las collaciones de San Salvador y San Nicolás de la Villa acudieron ante el rey en Burgos para pedirle su intervención por los muchos:

robos e furtos, e muertes de omnes, e fuerças de mugeres, e quebrantamientos de casas e otros malefiçios ${ }^{49}$.

Así pues, los enfrentamientos en la ciudad habían comenzado, y, aparentemente, los diversos bandos en contienda se servían de "rufianes e vagamundos" que iban "armados con fojas e adargas e escudos e lanças e ballestas e otras armas". Sin duda el armamento más propio de un soldado que de un ladrón o salteador. De hecho, los disturbios estaban causados por gentes del mismo cabildo ${ }^{50}$. Parece poco arriesgado afirmar que, por entonces, los problemas para los Baena ya habían comenzado en la misma ciudad de Córdoba.

Como vemos, la situación evolucionaba de forma muy parecida a lo que ocurría en el norte, donde Barrientos, el príncipe y los partidarios regios ya movían tropas y casi llegaban al enfrentamiento abierto con el príncipe, llegando a lograr la liberación del rey ${ }^{51}$.

Además, los rebeldes debían comenzar a tener apuros económicos, o ante la inminente llegada de tropas rivales trataban de guarecerse y aprovisionarse. Así, en la mencionada queja que los jurados presentaban al rey, también se indicaba que:

\footnotetext{
${ }^{46}$ Ibídem, citando AM Murcia, letg. 3762, nº 67.

${ }^{47}$ Ibídem, p. 348.

${ }^{48}$ I. SANZ SANCHO, «Los obispos del siglo xv», p. 617, cita las actas capitulares del cabildo, pero sin indicar más localización que la fecha.

${ }^{49}$ F. Mazo Romero, «Problemas internos y tensiones sociales...», p. 91, citando y siguiendo AMCO, Archivo de los señor es jurados de Cór doba, Disposiciones normativas, Reales provisiones, J-0001-046.

${ }^{50}$ Ibídem.

${ }^{51}$ L. Galíndez de Carvajal, Crónica del serenísimo príncipe..., pp. 622-623.
} 
El conçejo e corregidor desta dicha çibdad echaron ympusiçión a la carne e vino que se vende en esta dicha çibdad e en su término, syn vuestro mandado, e se coge e leva agora ${ }^{52}$.

Este dato nos hace pensar, además, en quién era el corregidor que había impuesto tales exacciones sobre la ciudad, y qué autoridad le había nombrado. ¿Acaso el infante había dejado al señor de Baena con tal condición como su representante? Es imposible saberlo sin más información.

En agosto aún sabemos que la ciudad seguía dominada por la nobleza y el obispo, quienes seguían intentando recaudar las rentas regias (aunque parece factible que los altercados hiciesen difícil su situación). Sabemos de ello precisamente por la resistencia que estaban comenzando a encontrar, y por la actitud abierta de oposición por parte de algunos miembros del cabildo, así como de algunas localidades de la región.

Algunos estaban en la ciudad de Córdoba, motivo por el que, posiblemente, fueron sometidos a prisión Pedro Fernández, canónigo, y Pedro de Torres, racionero, al menos desde el 24 de julio y por orden del obispo ${ }^{53}$. Fuera de la ciudad la actuación de algunos capitulares era abiertamente hostil al obispo y rebeldes; así, el día 5 de agosto de 1444 se presentaba ante Fuenteovejuna Fernando Ruiz de Aguayo, chantre de Córdoba ${ }^{54}$. Éste, que era capellán real ${ }^{55}$ y uno de los principales opositores al obispo Sancho de Rojas ${ }^{56}$, llegó a la villa por el camino de Córdoba, acompañado de ballesteros y lanceros, y se encontró con los muros y puertas guardados por hombres de caballo, lanceros y peones que le dijeron que volviese por donde venía, puesto que ellos guardaban Fuenteovejuna por el rey. Él les contestó que también servía al rey y al parecer fue reconocido, pues le dejaron pasar $^{57}$. Una vez dentro de la villa, en la plaza mayor, en presencia de los alcaldes, justicias y jurados, y de un escribano que dio fe de todo ello, el chantre indicó cómo se habían mandado recoger y recaudar ciertas cantidades de maravedíes en contra de la voluntad del rey y en su deservicio, por lo que como:

yo soy venido aquí con entençión de servir al rrey nuestro señor e fasiéndole serviçio, digo e rrequiero a estos dichos oficiales e a cada uno dellos por sí, si neçesario es, que ellos juntos con el conçejo desta dicha villa la tengan a la guarda e rrecabdo para el dicho señor rrey e para su espreso mandado, e que si algún rrepartimiento o rrepartimientos son puestos so esta dicha villa por mandado de aquellos cavalleros que están en la dicha çibdat contra voluntad del dicho señor rrey e contra todo su serviçio

${ }^{52}$ F. Mazo Romero, «Problemas internos y tensiones sociales...», p. 106, misma signatura de archivo.

${ }^{53}$ I. SAnZ SAncho, «Los obispos del siglo xv», p. 622.

${ }^{54} \mathrm{ACC}, J H S, \mathrm{n}^{\mathbf{0}} 398$.

${ }^{55}$ Ibídem, no 410.

${ }^{56}$ I. SAnz SAncho, «Los obispos del siglo xv», p. 618.

${ }^{57} \mathrm{ACC}, J H S, \mathrm{n}^{\circ} 398$. 
que les non cojan e algunos maravedís o prendas están cojidos e prendados que luego se den e tornen a sus dueños ${ }^{58}$

Así pues, vemos cómo Córdoba aún estaba, a la altura de principios de agosto de 1444, en manos de la nobleza rebelde, y que se seguía intentado recaudar dinero, sin duda para aprestarse a la defensa. No cabe duda que el infante Enrique podía huir, pero los nobles cordobeses que se habían implicado en la acción no tenían muchas opciones. Sin duda, la imposición del entredicho por parte del obispo Sancho de Rojas sobre la ciudad tenía que ver con la pérdida del control sobre la misma. El infante había abandonado Andalucía y había dejado al señor de Baena al frente de su bando (lo que muestra hasta qué punto el mariscal había sido importante en la expedición andaluza).

El rey, que ya estaba libre, tomó buena nota de todo ello, y ese mismo mes de octubre arrebató a Diego Fernández de Mendoza el cargo de alguacil mayor de Córdoba, entregándoselo a su rival Pedro Fernández de Córdoba, señor de Aguilar ${ }^{59}$. Prácticamente al tiempo que el chantre de Córdoba acudía a Fuenteovejuna, el cabildo apeló ante el arzobispo de Toledo, metropolitano del obispado de Córdoba, por el entredicho que había impuesto el prelado, lo que fue aceptado por el provisor de la sede (el hecho de que el arzobispo Gutierre de Toledo ya se hubiese concordado con el bando regio tuvo que tener un peso notable en tal hecho) ${ }^{60}$. Como vemos, el cabildo actuó entonces en contra de los intereses y las órdenes del obispo, continuando la línea empezada en julio, y mostrándose ya como un cabildo poco sumiso.

Como se sabe, el prelado y su familia abandonaron Córdoba, refugiándose en Baena. Tal vez no fuese porque les expulsase Pedro Fernández de Córdoba, pero parece claro que iban a estar mucho más seguros en sus posesiones ${ }^{61}$. Al menos el 7 de diciembre de 1444 ya estaba allí, y no parecía querer acercarse a Córdoba y a la catedral ni siquiera para ciertos actos religiosos ${ }^{62}$.

\section{LAS CONSECUENCIAS DE LA REBELDÍA}

El año 1445 supuso un periodo de recuperación para la monarquía. El rey Juan II no dudaría en actuar contra aquellos que habían colaborado con sus enemigos, como ya hemos visto en el caso del señor de Baena, perdiendo sus cargos en Córdoba. Por ejemplo, también el obispo de Jaén se vería atacado por el concejo, así, en 1445 Gonzalo de Estúñiga tuvo que defender su castillo de Begíjar ante los intentos del concejo de Baeza de tomarlo, bajo la excusa de que era suyo, en lo que podemos ver

${ }^{58} \mathrm{ACC}, J H S, \mathrm{n}^{\circ} 399$.

${ }^{59}$ M.C. Quintanilla Raso, Nobleza y señorios..., p. 94.

${ }^{60}$ ACC, Secretaría, Actas, libro I, f. 44r.

${ }^{61}$ I. SAnz SANCHO, «Los obispos del siglo xv», p. 624.

${ }^{62}$ En ese momento solicitaba al cabildo que le remitiesen ciertos atuendos religiosos puesto que quería otorgar las órdenes a ciertas personas en Baena, J.M. Nieto Cumplido, Corpus medievale, 1444 (III), 1444, 12, 07, citando A C Córdoba, Secretaría, Libros de Actas, Libro I. 
una represalia por su colaboración con el infante Enrique ${ }^{63}$. Hay que tener en cuenta que era momento de ofensiva regia para recuperar la situación anterior al Golpe de Rámaga, en lo cual tenía una notable importancia la imagen que se tenía del rey, y las Cortes participarían activamente en su recuperación ${ }^{64}$. En Córdoba la recuperación de la imagen del poder regio pasaba por castigar a los que habían colaborado con sus enemigos. Por un lado sabemos que la familia Montemayor se vio atacada por los Aguilar ${ }^{65}$. Aunque uno de los principales acosos se dio contra el prelado Sancho de Rojas, quien se vería perjudicado por la actuación regia.

E1 5 de febrero de 1445 el monarca tomaría la iniciativa en lo referente al obispo Sancho de Rojas. Ese día escribía al cabildo de Córdoba para ordenarle que pusiesen a buen recaudo los frutos, rentas, bienes y casas pertenecientes al obispo, y que los administrasen y tuviesen en secuestro sin que se enajenase ni disipase nada ${ }^{66}$. El cabildo no sólo obedeció la carta, sino que la cumplió. Hay que tener en cuenta que en esos momentos en el norte del reino se maniobraba ya buscando el enfrentamiento con los infantes y sus partidarios. De esta forma, se buscaba ahogar económicamente al obispo de Córdoba, sin duda para evitar su posible participación en apoyo de los infantes (además de como clara represalia por su actuación). Es posible que se planteasen otro tipo de acciones por parte regia, pues el monarca había puesto recientemente bajo la misma situación las rentas episcopales de Coria, en su intento de que la sede fuese entregada a Fernando de Sotomayor y no a quien había nombrado el papa ${ }^{67}$, con lo que es posible que el rey se plantease conseguir la destitución del prelado rebelde.

¿Acaso acudió el monarca a Roma? No sería la primera ocasión en la que Juan II recurría a los papas para actuar contra prelados castellanos que actuaban en contra de sus intereses. Ya en la década de los años veinte del siglo lo había hecho con dos prelados que habían sido visibles y pertinaces partidarios de los infantes de Aragón, como fueron los casos de Juan Vázquez Cepeda (obispo de Segovia) y Martín de los Galos (obispo de Coria) ${ }^{68}$. Y en esos mismos momentos ocurría lo mismo con Pedro de Castilla, que se había alzado al tiempo que Sancho de Rojas en $1439^{69}$.

${ }^{63}$ J. Rodríguez Molina, El obispado de Baeza-Jaén. Or ganización y economía diocesana (siglos XIII-XVI), Jaén, 1986, p. 47

${ }^{64}$ En las Cortes de 1445 se indicaba que el rey era ungido de Dios y que como tal, cualquier resistencia al monarca era inaceptable, Cortes de los antiguos r reinos de León y Castilla, ed. de la Real Academia de la Historia, Madrid, 1986, III, p. 458.

${ }^{65}$ I. SAnz SANCHO, «Los obispos del siglo XV», p. 618.

${ }^{66}$ Archivo Capitular de Córdoba, Secretaría, Actas, Libro I, f. 50v.

${ }^{67}$ Sobre este conflicto véase: O. Villarroel GonzÁlez, «Un ejemplo de la intervención regia en las elecciones episcopales. Fernando de Sotomayor, electo de Coria», Revista de Estudios Extremeños, LVIII $(58,2002)$, pp. 1031-1045.

${ }^{68} \mathrm{O}$. Villarroel González, El rey y la Iglesia castellana. Relaciones de poder en época de Juan II (1406-1454), Madrid, 2011, pp. 260 y ss.

${ }^{69}$ Ibídem, véase también O. Villarroel GonZÁlez, «El reflejo léxico de las posturas políticas: vaivenes políticos de un prelado de sangre regia», Espacio Tiempo y Forma, 20 (2007), pp. 265-287; así como el más antiguo «Pedro de Castilla (1394-1461): un obispo de Osma al servicio de la monarquía», Celtiberia, 95 (2001), pp. 133-162. 
De hecho en los meses y años siguientes podemos comprobar cómo se siguió actuando contra él desde diversos ámbitos, pudiéndose observar y apreciar una clara influencia regia al respecto. En mayo de 1446 el prelado seguía refugiado en Baena y debía estar pasando apuros económicos, puesto que solicitaba ayuda al cabildo cordobés (reflejada en $15.000 \mathrm{mrs}$.) por la gran necesidad que tenía ${ }^{70}$. Sea como forma de presión, sea porque el cabildo se negó, impuso un subsidio sobre la sede para conseguir dinero bajo la amenaza de penas canónicas. Es posible que fuese lo primero, puesto que en junio de ese mismo año retiró las amenazas, aunque aparentemente mantuvo el subsidio ${ }^{71}$.

Unos meses antes tenemos noticia de la principal actuación regia contra Sancho de Rojas, y que nos hace pensar que tal vez llegó a plantearse intentar arrebatarle la sede. El día 8 de febrero de 1446 el papa Eugenio IV escribía un breve dirigido al prelado por el cual le ordenaba acudir a Roma en cuanto leyese la orden ${ }^{72}$. El documento no indica más, pero el contexto político, así como el hecho de que Pedro de Castilla, el otro obispo sublevado, también fuese convocado a Curia por el papa ${ }^{73}$, nos viene a indicar que posiblemente el rey había solicitado al pontífice su intervención $^{74}$. ¿Acudió a Roma? Al menos no en los meses siguientes, como hemos visto. Esta actuación contra el prelado es posible, a fin de cuentas Sancho de Rojas había sido un eficaz colaborador de los infantes desde los primeros momentos del conflicto en 1439, cuando aún era obispo de Astorga ${ }^{75}$, pudiendo decirse que fue uno de los más destacados rivales regios.

El prelado, evidentemente, también trató de defenderse. En agosto de 1447 sabemos que el prelado ordenó a Fernán Ruiz de Aguayo (chantre de la catedral, capellán real y activo defensor del bando regio, como hemos visto) diversas cosas que iban contra derecho y bajo la amenaza de penas canónicas. Por ello el chantre recurrió al arzobispado de Toledo, que intervino a su favor ${ }^{76}$. Este ataque ya se había iniciado en 1447, pues sabemos que el 31 de agosto de ese año el obispo intentaba exigir al chantre que cumpliese las obligaciones antiguas de ese cargo, sin tener en cuenta que en esos momentos era una dignidad más, y no un cargo ${ }^{77}$. El chantre se defendió alegando que iba contra derecho, puesto que ninguno de sus antecesores había ejercido tales funciones, que quedaban en manos del sochantre ${ }^{78}$.

\footnotetext{
${ }^{70}$ ACC, Secretaría, Libros de Actas, Libro I, f. $74 \mathrm{v}$.

${ }^{71}$ Ibídem, f. $75 \mathrm{v}$.

${ }^{72}$ ASV, Reg. Vat., 367, f. $177 \mathrm{v}$.

${ }^{73}$ O. Villarroel GonzÁlez, «El reflejo léxico...», (en prensa), la citación en ASV, Reg. Vat., 359, ff. 131v-132r; documento publicado por V. Beltrán de Heredia, Bulario de la Universidad de Salamanca, II, doc. 996, p. 484.

${ }^{74}$ Sobre la similitud de ambos casos véase: O. Villarroel Gonź́Lez, El rey y la Iglesia castellana..., pp. 282-283.

${ }^{75}$ Véase al respecto: ibídem, p. 730.

${ }^{76}$ ACC, Caj. M., n. ${ }^{\circ} 304$.

${ }^{77}$ En concreto le exigía que entonase los cánticos en las procesiones y en el coro: ibídem.

${ }^{78}$ I. Sanz SAncho, La Iglesia de Córdoba (1236-1454)..., p. 188.
} 


\section{A MODO DE CONCLUSIÓN}

Como hemos podido ver a lo largo de este breve estudio, como fue habitual a lo largo de la Baja Edad Media en la Corona de Castilla, las alteraciones cordobesas fueron un reflejo de los conflictos políticos que se desarrollaron en el conjunto del reino. En este sentido, el caso estudiado es un ejemplo más, en el que los diversos bandos nobiliarios se ven enfrentados en el marco urbano a la vez que aquellos con los que mantienen una alianza política se enfrentan en el conjunto del reino. Sin embargo, en esta ocasión, la entrada del infante en Andalucía entre 1443 y 1444, nos encontramos con una serie de diferencias que le prestan una serie de características muy definidas.

En primer lugar se trataba de una auténtica invasión desde el interior. Los grupos nobiliarios se vieron en la necesidad de resistirse o unirse a un grupo nobiliario que tenía bajo su poder al rey y que estaba poniendo bajo su control manu militari todo el sur del reino castellano. Sin tener en cuenta las connotaciones que esto supone en cuanto a los propios objetivos que tal ocupación podía tener, no cabe duda de que los enfrentamientos y los recursos movilizados no eran los mismos que se habían dado en otras ocasiones. Se movilizaron tropas para participar en la conquista, se impusieron exacciones que se presentaron como impuestos regios pero que ni habían sido establecidos por el poder real de Juan II ni estaban dirigidos a sus arcas, e, incluso, es posible que se produjesen nombramientos de oficiales regios al margen del propio rey, como hemos visto en el caso del corregidor de Córdoba.

En segundo lugar, los eclesiásticos jugaron un papel muy importante, y transplantaron a sus propios ámbitos el enfrentamiento general que se estaba viviendo en el conjunto de Castilla y en la propia Córdoba. A este respecto, incluso se puede afirmar que algunos eclesiásticos jugaron un papel fundamental dentro de todas las acciones emprendidas, tanto para apoyar al infante Enrique como para defender al monarca, siendo los principales ejemplos el obispo Sancho de Rojas y el chantre Fernán Ruiz de Aguayo. También es digno de mención cómo la lucha por el control de la ciudad se trasplantó al propio cabildo, que, pese a todo, siempre se mostró más bien contrario a las intenciones del obispo, pues hemos visto que tuvo mucha dificultad para poder controlarlo.

En tercer lugar, el propio monarca fue consciente de todo esto, pues una vez recuperado el control sobre el reino no dudó en actuar en consonancia, buscando castigar contra aquellos que se habían opuesto a su autoridad colaborando con el infante, tanto a los laicos como a los eclesiásticos, no dudando en actuar, incluso, contra el mismo obispo, perjudicándole en cuestiones económicas e, incluso, recurriendo al sumo pontífice.

Así pues, pese a que nos encontramos ante un ejemplo más de extensión de los conflictos del reino al ámbito local, no cabe duda de que la situación general de la Corona de Castilla, así como el tipo de enfrentamiento que se estaba desarrollando en el conjunto de la los reinos de Juan II, otorgaron un matiz muy distinto a la situación que se extendió por Andalucía, y Córdoba en concreto, durante el periodo de tiempo que precedió y sucedió a la expedición del infante Enrique. Un enfrentamiento que, en el ámbito cordobés y al igual que en otros ámbitos urbanos, llevó a 
la participación activa de todos los estamentos, y que en el caso que se ha analizado cristalizó en el ostracismo político, si bien momentáneo, de la casa de Baena, por el apoyo prestado al bando del infante Enrique y contrario al monarca reinante. 